\title{
Spinal Mitogen-Activated Protein Kinase Phosphatase-3 (MKP-3) is Necessary for the Normal Resolution of Mechanical Allodynia in a Mouse Model of Acute Postoperative Pain
}

\author{
Madhurima Saha, ${ }^{1}$ Sladjana Skopelja, ${ }^{1}$ Elena Martinez, ${ }^{1}$ Daniel L. Alvarez, ${ }^{1}$ Brenna S. Liponis, ${ }^{1}$ \\ and E. Alfonso Romero-Sandoval ${ }^{1,2,3}$ \\ ${ }^{1}$ Department of Anesthesiology and 2Department of Pharmacology/Toxicology, Geisel School of Medicine at Dartmouth, Hanover, New Hampshire 03755, \\ and ${ }^{3}$ Department of Pharmaceutical and Administrative Sciences, Presbyterian College School of Pharmacy, Clinton, South Carolina 29325
}

The mechanisms that drive the normal resolution of acute postoperative pain are not completely understood. We hypothesize a pivotal role of a major spinal mitogen-activated protein kinase (MAPKs) regulator, MAPK phosphatase (MKP)-3, in the resolution of postoperative pain. We used wild-type and MKP-3 knock-out (KO) mice, a paw incision model of acute postoperative pain, and behavioral and molecular biology experiments. We observed persistent mechanical allodynia in mice lacking MKP-3 (postoperative day 21), concurrently with persistent phosphorylation of spinal p38 and extracellular signal-regulated kinases (ERK)-1/2 on postoperative day 12 , while both MAPK phosphorylation and allodynia resolved on postoperative day 7 in wild-type mice. Spinal p-ERK was expressed mainly in neurons and microglia, while spinal p-p38 was expressed mostly in microglia in MKP-3 KO mice, and their selective pharmacological inhibition reduced the persistent allodynia observed in these mice. Our findings strongly suggest that dysregulation of MKP-3 prevents spontaneous resolution of acute postoperative pain and drives its transition to persistent pain via persistent neuronal and microglial MAPK phosphorylation in the spinal cord.

\section{Introduction}

While acute postsurgical pain generally resolves if treated effectively, numerous common surgeries are followed by persistent postoperative pain in $10-50 \%$ of patients, with an estimated 350,000 new cases occurring annually in the United States ( $\mathrm{Ku}$ pers and Kehlet, 2006). However, the pathophysiological mechanisms of postoperative pain, and its frequent transition to chronic pain, are poorly understood (Burke and Shorten, 2009; Katz and Seltzer, 2009). The phosphorylation of spinal mitogenactivated protein kinases (MAPKs), such as p38 and extracellular signal-regulated kinases (ERK)-1/2, is instrumental in the development and maintenance of mechanical hypersensitivity in models of both chronic neuropathic pain (Ji et al., 2009) and acute postoperative pain (Wen et al., 2009). Furthermore, our laboratory and others have shown that the phosphorylated form of $\mathrm{p} 38$ (p-p38) plays an important role in the mechanisms of persistent

\footnotetext{
Received Dec. 6, 2012; revised Sept. 13, 2013; accepted Sept. 24, 2013.

Author contributions: E.A.R.-S. designed research; M.S., S.S., E.M., D.L.A., B.S.L., and E.A.R.-S. performed research; M.S., S.S., E.M., D.L.A., B.S.L., and E.A.R.-S. analyzed data; M.S., S.S., E.M., and E.A.R.-S. wrote the paper.

Supported by the Rita Allen Foundation \& American Pain Society 2011 Pain Grant (E.A.R.-S.), Hitchcock Foundation Award 2011-2012 (E.A.R.-S.), James 0. Freedman Undergraduate Presidential Scholars Program (B.S.L.), and Trygve E. Myhren 1958 Tuck 1959 Undergraduate Research Fund (D.L.A.). We thank Beth Wilkerson, Presbyterian College School of Pharmacy, for edits and revision.

The authors declare no competing financial interests.

Correspondence should be addressed to Dr. Edgar Alfonso Romero-Sandoval, Presbyterian College School of Pharmacy, 307 North Broad Street, Clinton, SC 29325. E-mail: asandoval@presby.edu.

DOI:10.1523/JNEUROSCI.5605-12.2013

Copyright $\odot 2013$ the authors $\quad 0270-6474 / 13 / 3317182-06 \$ 15.00 / 0$
}

postoperative pain in the spinal cord of rodents (Alkaitis et al., 2010; Huang et al., 2011). However, it is unclear why spinal MAPK phosphorylation is perpetuated in chronic pain models ( $\mathrm{Ji}$ and Suter, 2007), why it resolves spontaneously within days in acute pain models (Wen et al., 2009), or why it remains for several weeks in persistent pain models (Alkaitis et al., 2010; Huang et al., 2011). It is possible that natural regulators of MAPKs, namely MAPK phosphatases (MKPs), underlie the mechanisms that drive the resolution of MAPK phosphorylation following surgery and therefore the resolution of acute postoperative pain. We hypothesize that dysregulation of MKP-3, a natural negative regulator of MAPKs, drives the transition from acute to persistent postoperative pain.

MAP kinase phosphatases are the main regulators of major MAPKs (ERK-1/2, p38, and c-Jun N-terminal kinase/stressactivated protein kinase (Owens and Keyse, 2007). MKPs are substrate specific, such that MKP-3 preferentially dephosphorylates p-ERK (Owens and Keyse, 2007). We have recently demonstrated the role of spinal MKP-1 or MKP-3 in the mechanisms underlying neuropathic pain in the rat (Landry et al., 2012; Ndong et al., 2012).

The clinical relevance of our interest in the MKP/MAPK pathways under pain conditions is based on the clinical trials showing that inhibition of $\mathrm{p}-\mathrm{p} 38$, one of the natural substrates of MKPs, effectively treats acute postoperative pain and chronic neuropathic pain in humans (Anand et al., 2011; Tong et al., 2012). 
A

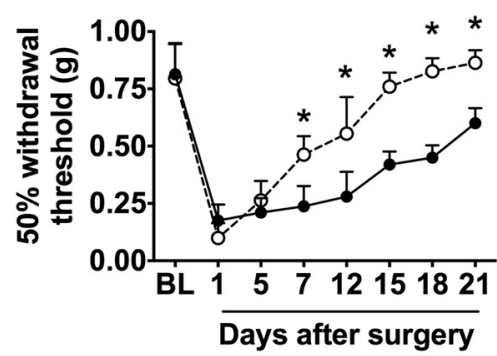

C

\section{Days after surgery}

BL $1 \begin{array}{llll}1 & 5 & 7 & 12\end{array}$

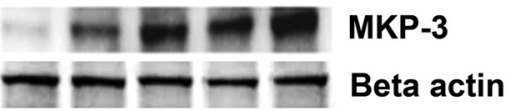

B

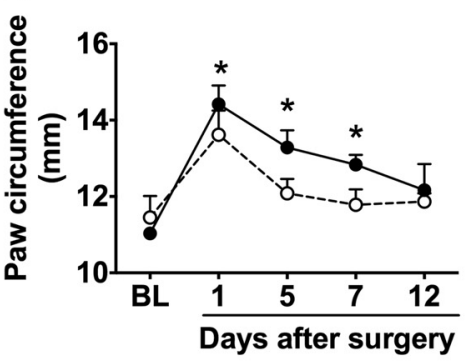

D

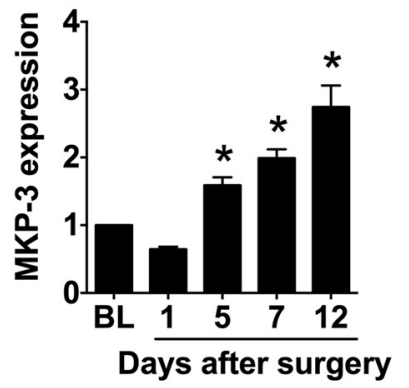

$\mathbf{F}$
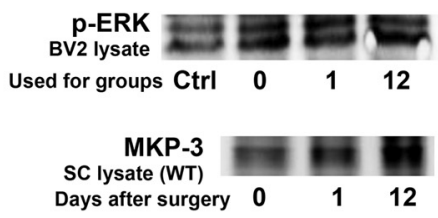

IP:p-ERK

from BV-2 cells

p-ERK

MKP-3

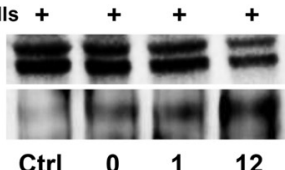

Days after surgery (IP:MKP-3 from WT spinal cords)

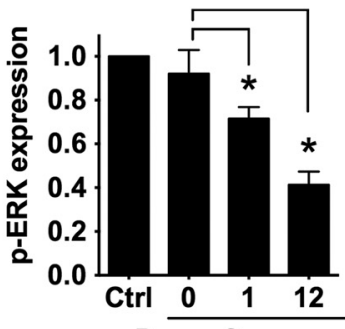

Days after surgery (IP:MKP-3 from WT spinal cords)

Figure 1. Fifty percent paw withdrawal threshold $(\boldsymbol{A})$ and paw circumference $(\boldsymbol{B})$ at baseline $(\mathrm{BL})$ and after paw incision on days $1-21$ or 1-12 in WT $(O, n=7-12)$ and MKP-3 KO mice $(\mathbf{O}, n=6-12)$; two-way ANOVA + Bonferroniposthoc analysis, ${ }^{*} p<0.05$ WT versus MKP-3 K0 group. Representative Western blotimage $(\boldsymbol{C})$ and quantification for MKP-3 $(\boldsymbol{D})$ expression in L5- $\mathrm{L} 6$ spinal cord of WT mice, naive and on days $1,5,7$, and 12 after paw incision surgery $(n=3)$; one-way ANOVA + Dunnett's post-test, ${ }^{*} p<0.05$ versus BL. Enzymatic activity assays of spinal MKP-1 from WT mice $(\boldsymbol{E})$, and spinal MKP-3 from WT mice $(\boldsymbol{F})$. In $\boldsymbol{E}$ and $\boldsymbol{F}$, representative Western blot image for p-ERK-1/2 obtained from LPS-stimulated BV-2 cell lysate and MKPs from spinal cord (SC) lysate from which immunoprecipitation (IP) was performed (top and center blots, respectively). The bottom blots in $\boldsymbol{E}$ and $\boldsymbol{F}$ show p-ERK-1/2 (quantified in combination) from LPSstimulated BV-2 cell by IPalone (Ctrl, control), or in the presence of MKP-1 or MKP-3 immunoprecipitated from L5-L6spinal cord (ipsilateral to surgery, WT mice), of naive (day 0 after surgery) or after paw incision surgery on postoperative days 1 or 12 . Representative Western blot images of spinal MKP-1 or MKP-3 obtained by IP are shown below IP pERK-1/2. For $\boldsymbol{E}$ and $\boldsymbol{F}$, one-way ANOVA + Dunnett's post-test, ${ }^{*} p<$ 0.05 versus naive (day 0 after surgery, $n=3$ /group).

\section{Materials and Methods}

Animals

Wild-type (WT, B6129SF2/J) and MKP-3 knock-out (KO, B6129X1Dusp6 TM1Jmol/J; The Jackson Laboratory) male and female (50- to

60-d-old) mice were used (Maillet et al., 2008). Mice were maintained in a $12 \mathrm{~h}$ light/dark cycle with ad libitum access to food and water. All animal procedures were approved by The Institutional Animal Care and Use Dartmouth Committee at Geisel School of Medicine at Dartmouth (Hanover, NH), and were performed in accordance with the Guidelines for Animal Experimentation of the International Association for the Study of Pain.

\section{Surgery and behavioral testing}

Paw incision was used as a model of postoperative pain in mice (Brennan et al., 1996; Pogatzki and Raja, 2003). Mechanical sensitivity was tested using von Frey filaments (Stoelting) and an up-down statistical method before the surgery (baseline), and on postoperative days $1,5,7,12,15,18$, and 21 , in both WT and $\mathrm{KO}$ mice, or in KO mice on day 12, and 0.5, 1 , and $2 \mathrm{~h}$ post MAPK inhibitors. Naive mice were used as controls. The experimenter was blinded to genotype and treatment groups.

\section{Peripheral inflammation}

Paw inflammation was assessed before the surgery and on postoperative days $1,5,7$, and 12 by measuring the circumference of the paw ipsilateral to surgery using a 4-0 silk thread passed through the center of the surgical incision (between both sutures), in both WT and MKP-3 KO mice. A statistically significant increase in the circumference of the paw versus basal levels was interpreted as inflammation.

\section{Drugs and intrathecal injections}

The MEK inhibitor, PD98059 (a blocker of phosphorylation of ERK) and p-p38 inhibitor SB239063 (Sigma) were diluted in dimethylsulfoxide and saline (1:1). PD98059 (6.682 $\mu \mathrm{g}$ [25 nmol], $5 \mu \mathrm{l}), \mathrm{SB} 239063(5 \mu \mathrm{g}, 5 \mu \mathrm{l})$, or vehicle $(5 \mu \mathrm{l})$ was administered intrathecally (Karim et al., 2001; Eijkelkamp et al., 2010) on postoperative day 12 in $\mathrm{KO}$ mice using a 30 gauge needle by lumbar puncture (Hylden and Wilcox, 1980). Brilliant Blue dye was administered with drugs or vehicle to confirm the correct administration of agents via intrathecal injection. The spinal cord tissues were collected after the last behavioral assessment.

\section{Tissue preparation and Western}

blot analysis

The animals were killed using isoflurane anesthesia (4\% in oxygen) and decapitation. The L5-L6 region of the spinal cord was collected and sonicated in PBS containing 1:1000 protease inhibitors (Sigma). Protein $(50 \mu \mathrm{g})$ was loaded to SDS PAGE (10\% gels; Bio-Rad) and transferred to nitrocellulose membranes (Bio$\mathrm{Rad})$. The membranes were blocked and incubated $\left(4^{\circ} \mathrm{C}\right)$ overnight in primary antibodies as follows (Landry et al., 2012; Ndong et al., 2012): rabbit anti-MKP-1 (1:500; Santa Cruz Biotechnology), rabbit anti-MKP-3 (1:3000; Cell Signaling Technology), mouse anti-pERK-1/2 (1:1000; Cell Signaling Technology), or rabbit anti-p-p38 (1: 1000 Cell Signaling Technology). The blots were then incubated in one of the following secondary antibodies: goat anti-mouse horseradish peroxidase (HRP)-conjugated antibody (1:3000; Bethyl Laboratories) or goat 
anti-rabbit HRP-conjugated antibody (1:3000; Pierce). Subsequently, the blots were washed and imaged with a Syngene G-Box (Synoptics). Some blots were stripped and reblotted with primary and secondary antibodies as previously described (Ndong et al., 2012). Band intensity was assessed using ImageJ software, using $\beta$-actin as the loading control.

\section{Immunoprecipitation and phosphatase} activity assay

Immunoprecipitation. The phosphatases (MKP-1 and MKP-3) were immunoprecipitated separately using rabbit anti-MKP-1 or goat anti-MKP-3 antibody (1:100; Santa Cruz Biotechnology). Protein A-conjugated magnetic beads (Life technologies) were incubated with the abovementioned antibodies for $2 \mathrm{~h}$ at $4^{\circ} \mathrm{C}$. Then, samples of $50 \mu \mathrm{g}$ of protein of L5-L6 ipsilateral spinal cord sections of WT or KO mice on postoperative days 0 (naive), 1 , and 12 were added to the beads conjugated with the phosphatase-specific antibodies in three different $0.5 \mathrm{ml}$ tubes. Beads conjugated with antibodies without spinal cord protein were the negative control. The preparations were rocked overnight at $4^{\circ} \mathrm{C}$. The use of hemisections of the spinal cord may result in a dilution of our samples, but this did not prevent the detection of significant changes among the groups studied.

For phosphatase substrate we used p-ERK from mouse microglial BV-2 cells. Confluent cell cultures (in flask) were treated with 1 $\mathrm{mg} / \mathrm{ml}$ lipopolysaccharide (LPS) for $1 \mathrm{~h}$ at $37^{\circ} \mathrm{C}$. The pelleted cells were sonicated and centrifuged, and the supernatants were collected. Rabbit anti-phospho-ERK antibody Sepharose-conjugated beads $(30 \mu \mathrm{l} / 500 \mu \mathrm{l}$ of BV-2 extract; Cell Signaling Technology) were added to the sample and rocked overnight at $4^{\circ} \mathrm{C}$.

Phosphatase activity assay. According to a concentration response curve for spinal MKPs (50 $\mu \mathrm{g}, 100 \mu \mathrm{g}$; or $200 \mu \mathrm{g}$ of total protein; data not shown), the optimum enzymatic activity of spinal cord MKP-1 and MKP-3 could be assessed using $50 \mu \mathrm{g}$ of total protein for $500 \mu \mathrm{l}$ of p-ERK from BV-2 extracts as substrate. Phosphatase and p-ERK were conjugated and incubated overnight at $4^{\circ} \mathrm{C}$. Then, samples were used for Western blot analyses as described earlier. The individual blots were incubated with mouse anti-p-ERK-1/2. For every Western blot we included a sample of immunoprecipitated p-ERK from BV-2 cells in the absence of spinal cord MKPs as the control group, which showed the amount of p-ERK in the absence of enzymatic activity of MKPs. The expression level of p-ERK in the presence of MKPs immunoprecipitated from spinal cords of naive mice (postoperative day 0 ) was used to estimate the basal enzymatic activity of MKPs in mice spinal cord. Therefore, a reduction of p-ERK expression relative to naive group reflects higher enzymatic activity of MKPs, and vice versa.

\section{Immunohistochemistry}

Mice were transcardially perfused under 2-3\% isoflurane in $\mathrm{O}_{2}$ anesthesia with $10 \mathrm{~mm}$ PBS $(\sim 150 \mathrm{ml})$ followed by $4 \%$ formaldehyde $(\sim 250 \mathrm{ml})$. The spinal cord L5-L6 regions were mounted in optimal cutting temperature compound (Sakura Finetek), frozen at $-80^{\circ} \mathrm{C}$, and then transversely cut to $20 \mu \mathrm{m}$ thickness. Spinal cord sections were blocked and dual staining was performed for the p-ERK-1/2 or p-p38 with cellular markers. The tissues were incubated overnight in monoclonal mouse anti-pERK (1:50; Cell Signaling Technology) with either rabbit anti-
Wild Type

MKP-3 KO

Days after surgery

Days after surgery

BL \begin{tabular}{lllllllll}
\hline 1 & 5 & 7 & 12 & $B L$ & 1 & 5 & 7 & 12
\end{tabular}
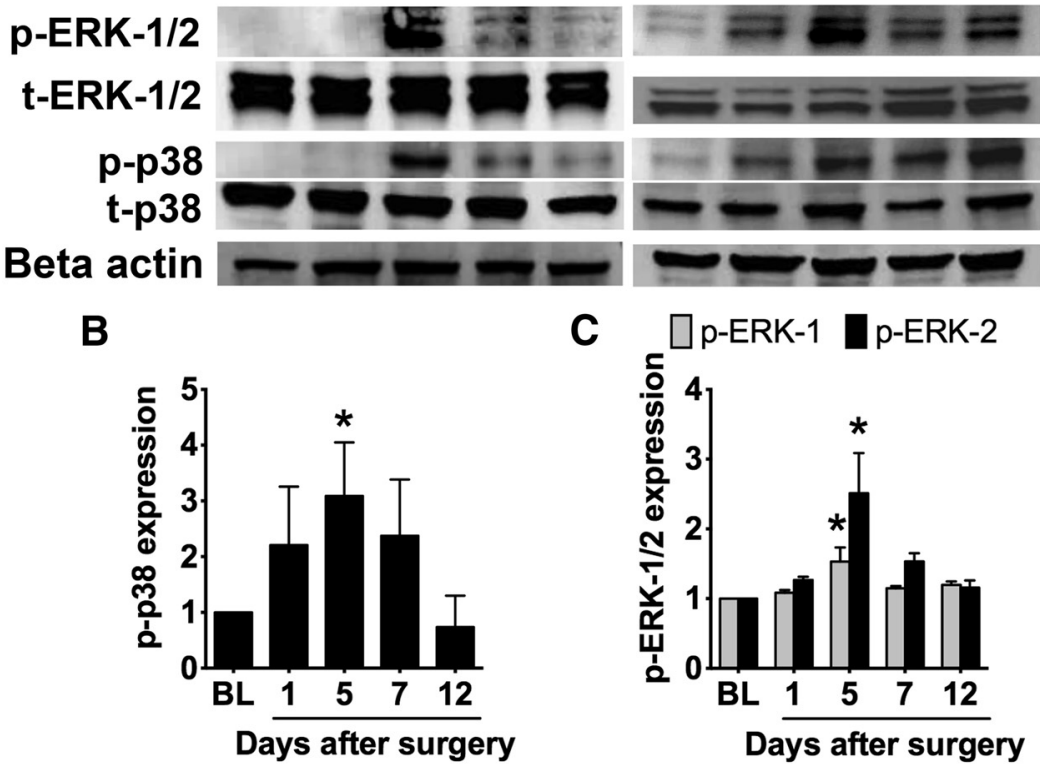

C $\quad$ p-ERK-1 $\square$-ERK-2

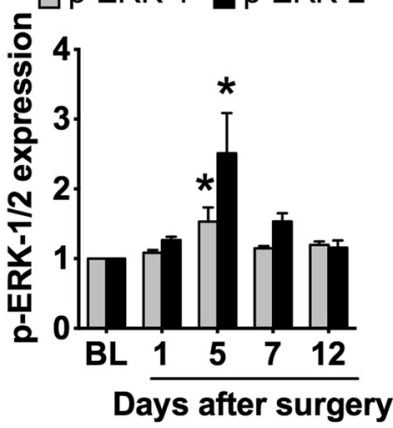

E

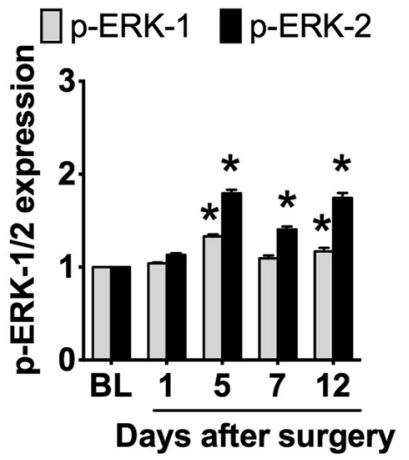

Figure 2. Representative Western blot image $(\boldsymbol{A})$ and quantification for p-p38 (B) and p-ERK-1/2 ( $\boldsymbol{C}$ expression in L5-L6 spinal cord of WT mice, and p-p38 (D) and p-ERK-1/2 (E) expression in L5-L6 spinal cord of MKP-3 KO mice, naive and on days 1,5, 7, and 12 after paw incision surgery $(n=3)$; one-way ANOVA + Dunnett's post-test, ${ }^{*} p<0.05$ versus baseline (BL; $n=3 /$ pgroup).

NeuN/Fox3 (1:10,000; Biosensis), rabbit anti-ionized calcium binding adaptor molecule-1 (Iba-1; marker for microglia, 1:1000; Wako), or rabbit anti-glial fibrillary acidic protein (GFAP; marker for astrocytes, 1:1000, Dako). The other set of tissues was incubated in monoclonal rabbit anti-p-p38 (1:50; Cell Signaling Technology) with either mouse anti-NeuN (1:10,000; Millipore Bioscience Research Reagents), mouse anti-CD11b (marker for microglia, 1:1000; Wako), or mouse anti-GFAP (1:400; Sigma). The sections were then incubated for $1 \mathrm{~h}$ in goat antirabbit Alexa 555 and goat anti-mouse Alexa 488 (1:250 and 1:8000, respectively; Invitrogen) and mounted in VectaShield medium (Vector Laboratories). Confocal microscopy was performed with a Zeiss LSM 510 Meta confocal microscope and images were prepared with the Zeiss LSM software and Adobe Photoshop software (Alkaitis et al., 2010). All images were taken from laminae I-II of dorsal horn spinal cord ipsilateral to paw incision.

\section{Statistical analysis}

All data are expressed as mean \pm SEM. Statistical analyses were performed using GraphPad Prism 5 (GraphPad Software). For behavior data analysis two-way ANOVA of repeated measurements was applied, followed by Bonferroni post hoc. One-way ANOVA, followed by Dunnett's post-test, was used to analyze differences of protein expression in 

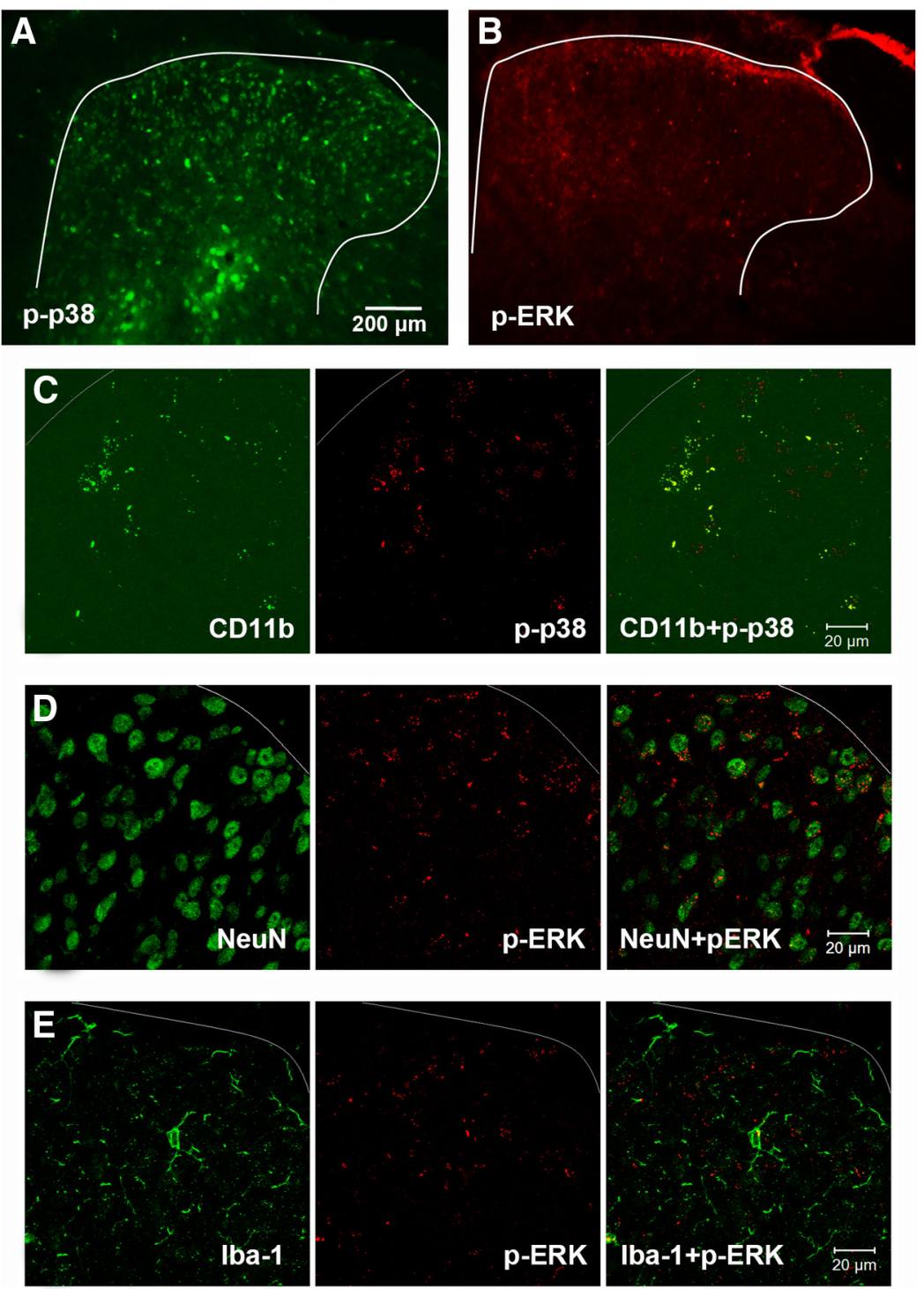

Figure 3. Immunofluorescent staining of p-p38 $(\boldsymbol{A})$ and $\mathrm{p}-\mathrm{ERK}(\boldsymbol{B})$ in dorsal horn spinal cord (L5-L6) ipsilateral to paw incision Confocal images of p-p38 staining (red) in CD11b-expressing microglia (green; $\boldsymbol{C}$. Confocal images of p-ERK staining (red) in NeuNexpressing neurons (green; $\boldsymbol{D}$ ) or in lba-1-expressing microglia (green; $\boldsymbol{E}$ ). All images were taken ipsilateral to paw incision $12 \mathrm{~d}$ after surgery in $\mathrm{KO}$ mice. All confocal images were taken in laminae I- Il of dorsal horn of L5-L6 spinal cord. Colocalization (merge) is shown in yellow/orange. P-p38 color (originally in green) was changed to red, and cellular marker color (originally in red) was changed to green to obtain a better visualization and for consistency with the other immunofluorescence data.

Western blot analyses between groups. A $p$ value $<0.05$ was considered statistically significant.

\section{Results}

Mechanical allodynia and paw inflammation

We did not observe any overtly altered behavior in MKP-3 KO mice compared with WT mice. Both strains gained weight at a normal rate at the ages they were used in this study. MKP-3 KO mice did not express MKP-3 in the spinal cord and spinal MKP-1 expression did not differ between WT and MKP-3 KO mice (data not shown).

Baseline mechanical withdrawal thresholds and paw incisioninduced mechanical hypersensitivity on postoperative day 1 did not differ between WT and MKP-3 KO mice (Fig. 1A). In WT mice this mechanical allodynia resolved with no intervention 7-12 d after surgery (Fig. 1A), as previously shown in mice (Pogatzki and Raja, 2003). In MKP-3 KO mice paw incision- induced mechanical allodynia persisted until postoperative day 21 (Fig. 1A).

Paw circumferences measured before surgery and paw incision-induced inflammation on postoperative day 1 did not differ between WT and MKP-3 KO mice (Fig. 1B). In WT mice, this paw inflammation resolved with no intervention on postoperative day 5 in accordance with the observed resolution of mechanical allodynia. In MKP-3 KO mice, paw incision-induced inflammation persisted on postoperative days 5 and day 7 and resolved on postoperative day 12 (Fig. 1B), in contrast to the still present mechanical allodynia at this time point. These data suggest that persistent postoperative allodynia in MKP-3 KO mice is not directly related to peripheral inflammation, which prompted us to seek a possible causative relationship within the molecular mechanisms at the spinal cord.

MKP-1 and MKP-3 expression, activity, and MAPK cellular localization in the spinal cord

We observed no significant changes in spinal cord MKP-1 expression at any studied time following paw incision (data not shown) in WT mice. However, spinal cord MKP-3 expression increased on days 5,7 , and 12 after surgery (Fig. $1 C, D$ ) in WT mice. Spinal MKP-1 enzymatic activity increased on postoperative day 1 , but not on postoperative day 12 (Fig. $1 E$ ) in WT mice. Spinal MKP-3 enzymatic activity enhanced on postoperative days 1 and 12 (Fig. $1 F$ ) in WT mice.

The expression of spinal MKP-1 in MKP-3 KO mice was enhanced on postoperative days 1 and 12 but not on days 5 and 7 following paw incision (data not shown). However, MKP-1 enzymatic activity from MKP-3 KO mice did not change following paw incision on days 1 and 12 (data not shown).

We then measured the levels of spinal MKP-1 and MKP-3 substrates following paw incision (Fig. 2A). As previously reported (Wen et al., 2009), we observed that spinal p-p38 expression was elevated on day 5 and returned to basal levels on days 7 and 12 following paw incision in WT mice (Fig. $2 B$ ). Similarly, spinal p-ERK-1/2 expression was enhanced on postoperative day 5 and returned to basal levels on day 7 following paw incision in WT mice (Fig. 2C). These data are in accordance with the changes observed in spinal MKP-1 and MKP-3 and with the initiation and resolution of postoperative mechanical allodynia observed in WT mice. In contrast, in MKP-3 KO mice, both spinal p-ERK-1/2 (Fig. 2D) and p-p38 (Fig. 2E) expression were enhanced on days 5, 7, and 12 after paw incision. These data are in accordance with the persistent mechanical hypersensitivity observed in MKP-3 KO mice following paw incision. 
A

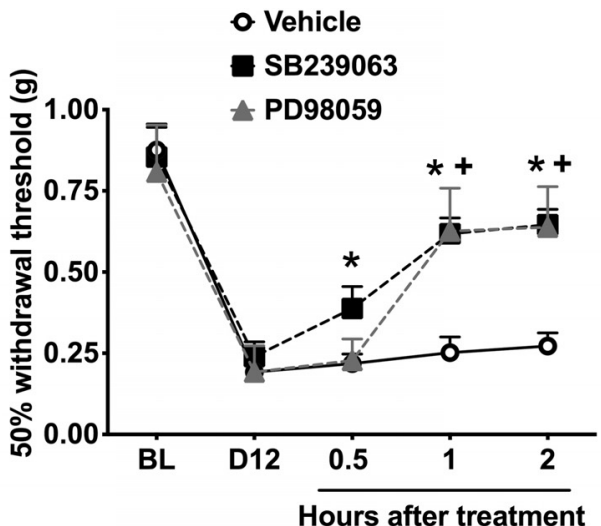

B

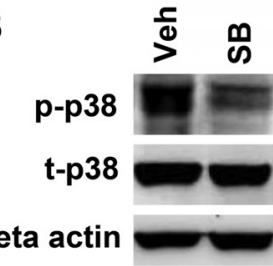

C

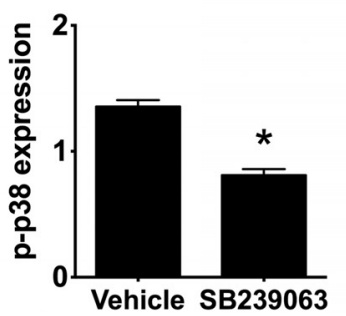

D

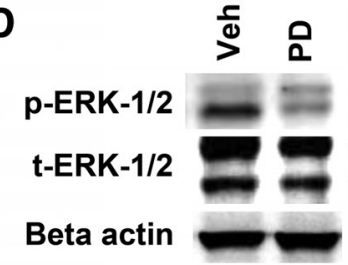

E

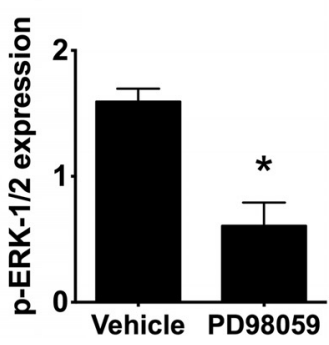

Figure 4. Effects of intrathecal injections of SB239063 (p-p38 inhibitor, $n=4)$, PD98059 (MEK$1 / 2$ inhibitor, $n=4)$, or vehicle $(n=4)$ in $50 \%$ paw withdrawal threshold $12 \mathrm{~d}$ after paw incision surgery in MKP-3 K0 mice $(\boldsymbol{A})$. Representative Western blot image of spinal p-p38 (B), or spinal p-ERK $(\boldsymbol{D})$ and Western blot quantification of spinal p-p38 (C) or spinal p-ERK (E). $\boldsymbol{A}$, Two-way ANOVA + Bonferroni post hoc analysis, ${ }^{*} p<0.05$ versus vehicle group. $B, C, 0$ ne-way ANOVA + Dunnett's post test, ${ }^{*} p<0.05$ versus vehicle group.

On day 12 after paw incision in MKP-3 KO mice, spinal p-38 was expressed in superficial and deep laminae of the dorsal horn (Fig. $3 A$ ), and spinal p-ERK was expressed mostly in laminae I-II (Fig. 3B). At this time point spinal p-p38 in laminae I-II was expressed mostly in microglia (Fig. 3C, CD11b-expressing cells), but not in neurons or astrocytes (data not shown), and spinal p-ERK in lamina I-II was expressed mostly in neurons (Fig. 3D, NeuN-expressing cells) and in some microglia (Fig. 3E, Iba-1expressing cells), but not in astrocytes (GFAP-expressing cells, data not shown).

\section{Spinal MAPK phosphorylation inhibition in MKP-3}

\section{KO animals}

The intrathecal administration of either SB239063 (5 $\mu \mathrm{g}$; p-p38 inhibitor) or PD98059 (6.682 $\mu \mathrm{g}$; MEK inhibitor) on postoperative day 12 in MKP-3 KO mice reverted the persistent mechanical allodynia induced by paw incision (Fig. $4 A$ ), and reduced the expression of p-p38 (Fig. $4 B, C$ ) and p-ERK-1/2 (Fig. 4D,E), respectively. These studies show the dependence of persistent postoperative allodynia on persistent spinal p-ERK-1/2 and p-p38.

\section{Discussion}

Our study demonstrates that mice lacking MKP-3 protein develop an abnormal persistent state of mechanical allodynia fol-

lowing plantar incision, which is concurrent with long-lasting spinal phosphorylation of ERK-1/2 and p38.

Spinal cord and peripheral MAPKs have been recognized as important contributors to the initiation of acute and persistent postoperative pain and perpetuation of chronic postsurgical pain in both animal models and human surgical conditions. MAPKs are tightly controlled by dual-specificity phosphatases (i.e., MKPs), which possess potent catalytic activity and directly dephosphorylate their substrate kinases. Through this mechanism that may be 100-1000 times more potent than kinase enzymatic activity (Jeffrey et al., 2007), MKPs, rather than upstream kinases phosphorylating MAPKs, are thought to direct the extent of MAPK phosphorylation (Bhalla et al., 2002) and, thus, to guide the resolution of inflammatory processes via MAPK dephosphorylation (Jeffrey et al., 2007). Our current findings are in accordance with the physiological roles of MKP-3, as we have shown in vitro (Romero-Sandoval et al., 2009).

Our findings specifically indicate that spinal cord MKP-3 is necessary for the normal dephosphorylation of spinal MAPK induced by peripheral surgery, which drives the resolution of acute postoperative allodynia. Although the mice used in this study (MKP-3 KO) are not conditional KOs, our approach allowed us to dissect peripheral and central roles of MKP-3/MAPK signaling. The lack of peripheral MKP-3 influences the resolution of peripheral inflammation. However, the persistent mechanical hypersensitivity when peripheral inflammation was resolved in MKP-3 KO mice indicates a key role of MKP-3 in spinal cord rather than in the periphery. Our findings strongly indicate that the absence of spinal cord MKP-3 is the main driving mechanism that allows the maintenance of spinal MAPK phosphorylation and allodynia. We confirmed this by specifically inhibiting the phosphorylation of ERK and p38 at the spinal cord level. Accordingly, we have shown that in a rat model of chronic pain, L5 nerve transection, spinal MKP-1 and MKP-3 levels are reduced, and that the restitution of spinal MKP-1 and/or MKP-3 using in vivo gene transfections or pharmacological approaches (using a cannabinoid receptor type 2 agonist, JWH015) prevents and treats the peripheral nerve injury-induced mechanical allodynia (Landry et al., 2012; Ndong et al., 2012). We do recognize the partial role of spinal MKP-3 in the resolution of acute postoperative pain, since other mechanisms have been also described, such as Protein Kinase M $\zeta$ (Asiedu et al., 2011). Additionally, our studies do not rule out the potential role of MKPs (Freeman et al., 2008) or other mechanisms in dorsal root ganglia.

Postoperative temporal changes in p-ERK expression further support the involvement of MKP-3, which preferentially dephosphorylates p-ERK over p-38 or p-JNK (Jeffrey et al., 2007). The phosphorylated form of ERK is necessary in transducing extracellular signals to intracellular transcriptional and post-translational events that propagate pain-related signaling cascades (Matsuoka and Yang, 2012), which are dynamically and progressively activated in spinal cord neurons, microglia, and in astrocytes (Zhuang et al., 2005). Our current findings suggest that spinal p-ERK-1/2, as well as p-p38, is necessary for perpetuation of behavioral hypersensitivity also in the context of acute postoperative pain and its transition to persistent pain.

Our immunohistochemical and confocal microscopic studies demonstrate that spinal cord neurons ( $p$-ERK) and microglia (both p-ERK and p-p38) acquire a pro-algesic phenotype (expression of MAPKs) in the absence of MKP-3 (KO conditions). These data strongly suggest that neuronal and microglial MKP-3 is pivotal in regulating MAPK phosphorylation in these cells. This assumption is in accordance with our 
previous findings in rats showing neuronal and microglial expression of spinal MKP-3 and its lack of expression in astrocytes (Landry et al., 2012).

\section{Conclusions}

Our data and the recognized biochemical and molecular regulatory properties render MKPs a potentially more suitable target for the timely and proper resolution of postoperative pain. Our data support the notion (Ndong et al., 2012) of developing specific MKP modulators (inducers) as potential therapies to prevent the development of persistent postoperative pain (Shipp et al., 2010; Bani-Hashem et al., 2011; Klongnoi et al., 2012).

\section{References}

Alkaitis MS, Solorzano C, Landry RP, Piomelli D, DeLeo JA, RomeroSandoval EA (2010) Evidence for a role of endocannabinoids, astrocytes and p38 phosphorylation in the resolution of postoperative pain. PLoS One 5:e10891. CrossRef Medline

Anand P, Shenoy R, Palmer JE, Baines AJ, Lai RY, Robertson J, Bird N, Ostenfeld T, Chizh BA (2011) Clinical trial of the p38 MAP kinase inhibitor dilmapimod in neuropathic pain following nerve injury. Eur J Pain 15:1040-1048. CrossRef Medline

Asiedu MN, Tillu DV, Melemedjian OK, Shy A, Sanoja R, Bodell B, Ghosh S, Porreca F, Price TJ (2011) Spinal protein kinase M zeta underlies the maintenance mechanism of persistent nociceptive sensitization. J Neurosci 31:6646-6653. CrossRef Medline

Bani-Hashem N, Hassan-Nasab B, Pour EA, Maleh PA, Nabavi A, Jabbari A (2011) Addition of intrathecal Dexamethasone to Bupivacaine for spinal anesthesia in orthopedic surgery. Saudi J Anaesth 5:382-386. CrossRef Medline

Bhalla US, Ram PT, Iyengar R (2002) MAP kinase phosphatase as a locus of flexibility in a mitogen-activated protein kinase signaling network. Science 297:1018-1023. CrossRef Medline

Brennan TJ, Vandermeulen EP, Gebhart GF (1996) Characterization of a rat model of incisional pain. Pain 64:493-501. CrossRef Medline

Burke S, Shorten GD (2009) When pain after surgery doesn't go away .... Biochem Soc Trans 37:318-322. CrossRef Medline

Eijkelkamp N, Heijnen CJ, Willemen HL, Deumens R, Joosten EA, Kleibeuker W, den Hartog IJ, van Velthoven CT, Nijboer C, Nassar MA, Dorn GW 2nd, Wood JN, Kavelaars A (2010) GRK2: a novel cell-specific regulator of severity and duration of inflammatory pain. J Neurosci 30:21382149. CrossRef Medline

Freeman SE, Patil VV, Durham PL (2008) Nitric oxide-proton stimulation of trigeminal ganglion neurons increases mitogen-activated protein kinase and phosphatase expression in neurons and satellite glial cells. Neuroscience 157:542-555. CrossRef Medline

Huang L, Gao YJ, Wang J, Strichartz G (2011) Shifts in cell-type expression accompany a diminishing role of spinal P38-mapkinase activation over time during prolonged postoperative pain. Anesthesiology 115:12811290. 1210.1097/ALN.1280b1013e31823499cc. Medline

Hylden JLK, Wilcox GL (1980) Intrathecal morphine in mice: a new technique. Eur J Pharmacol 67:313-316. CrossRef Medline

Jeffrey KL, Camps M, Rommel C, Mackay CR (2007) Targeting dualspecificity phosphatases: manipulating MAP kinase signalling and immune responses. Nat Rev Drug Discov 6:391-403. CrossRef Medline

Ji RR, Suter MR (2007) p38 MAPK, microglial signaling, and neuropathic pain. Mol Pain 3:33. CrossRef Medline
Ji R-R, Gereau RW 4th, Malcangio M, Strichartz GR (2009) MAP kinase and pain. Brain Res Rev 60:135-148. CrossRef Medline

Karim F, Wang CC, Gereau RW 4th (2001) Metabotropic glutamate receptor subtypes 1 and 5 are activators of extracellular signal-regulated kinase signaling required for inflammatory pain in mice. J Neurosci 21:37713779. Medline

Katz J, Seltzer Z (2009) Transition from acute to chronic postsurgical pain: risk factors and protective factors. Expert Rev Neurother 9:723-744. CrossRef Medline

Klongnoi B, Kaewpradub P, Boonsiriseth K, Wongsirichat N (2012) Effect of single dose preoperative intramuscular dexamethasone injection on lower impacted third molar surgery. Int J Oral Maxillofac Surg 41:376 379. CrossRef Medline

Kupers R, Kehlet H (2006) Brain imaging of clinical pain states: a critical review and strategies for future studies. Lancet Neurol 5:1033-1044. CrossRef Medline

Landry RP, Martinez E, DeLeo JA, Romero-Sandoval EA (2012) Spinal cannabinoid receptor type 2 agonist reduces mechanical allodynia and induces mitogen-activated protein kinase phosphatases in a rat model of neuropathic pain. J Pain 13:836-848. CrossRef Medline

Maillet M, Purcell NH, Sargent MA, York AJ, Bueno OF, Molkentin JD (2008) DUSP6 (MKP3) null mice show enhanced ERK1/2 phosphorylation at baseline and increased myocyte proliferation in the heart affecting disease susceptibility. J Biol Chem 283:31246-31255. CrossRef Medline

Matsuoka Y, Yang J (2012) Selective inhibition of extracellular signalregulated kinases $1 / 2$ blocks nerve growth factor to brain-derived neurotrophic factor signaling and suppresses the development of and reverses already established pain behavior in rats. Neuroscience 206:224-236. CrossRef Medline

Ndong C, Landry R, DeLeo JA, Romero-Sandoval EA (2012) Mitogen activated protein kinase phosphatase-1 prevents the development of tactile sensitivity in a rodent model of neuropathic pain. Mol Pain 8:34. CrossRef Medline

Owens DM, Keyse SM (2007) Differential regulation of MAP kinase signalling by dual-specificity protein phosphatases. Oncogene 26:3203-3213. CrossRef Medline

Pogatzki EM, Raja SN (2003) A mouse model of incisional pain. Anesthesiology 99:1023-1027. CrossRef Medline

Romero-Sandoval E, Horvath R, Landry RP, DeLeo J (2009) Cannabinoid receptor type 2 activation induces a microglial anti-inflammatory phenotype and reduces migration via MKP induction and ERK dephosphorylation. Mol Pain 5:25. CrossRef Medline

Shipp LE, Lee JV, Yu CY, Pufall M, Zhang P, Scott DK, Wang JC (2010) Transcriptional regulation of human dual specificity protein phosphatase 1 (DUSP1) gene by glucocorticoids. PLoS One 5:e13754. CrossRef Medline

Tong SE, Daniels SE, Black P, Chang S, Protter A, Desjardins PJ (2012) Novel p38 $\alpha$ mitogen-activated protein kinase inhibitor shows analgesic efficacy in acute postsurgical dental pain. J Clin Pharmacol 52:717-728. CrossRef Medline

Wen YR, Suter MR, Ji RR, Yeh GC, Wu YS, Wang KC, Kohno T, Sun WZ, Wang CC (2009) Activation of p38 mitogen-activated protein kinase in spinal microglia contributes to incision-induced mechanical allodynia. Anesthesiology 110:155165. 110.1097/ALN.1090b1013e318190bc318116. CrossRef Medline

Zhuang ZY, Gerner P, Woolf CJ, Ji RR (2005) ERK is sequentially activated in neurons, microglia, and astrocytes by spinal nerve ligation and contributes to mechanical allodynia in this neuropathic pain model. Pain 114: 149-159. CrossRef Medline 